\title{
Waste Monitoring System for Effluents
}

\section{Los Alamos NATIONAL LABORATORY}

Los Alamos National Laboratory is operated by the University of California for the United States Department of Energy under contract W-7405-ENG-36. 


\section{Edited by Vaikunth M. Stewwart, Group CIC-1}

:

An Affirmative Action/Equal Opportunity Employer

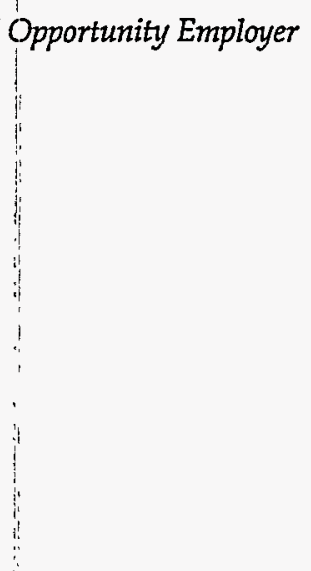

This report was prepared as an account of work sponsored by an agency of the United States Government. Neither The Regents of the University of California, the United States Government nor any agency thereof, nor any of their employees, makes any warranty, express or implied, or assumes any legal liability or responsibility for the accuracy, completeness, or usefulness of any information, apparatus, product, or process disclosed, or represents that its use would not infringe privately owned rights. Reference herein to any specific commercial product, process, or service by trade name, trademark, manufacturer, or otherwise, does not necessarily constitute or imply its endorsement, recommendation, or favoring by The Regents of the University of Califormia, the United States Government, or any agency thereof. The views and opinions of authors expressed herein do not necessarily state or reflect those of The Regents of the University of California, the United States Government, or any agency thereof. 


\section{DISCLAIMER}

Portions of this document may be illegible in electronic image products. Images are produced from the best available original document. 
Waste Monitoring System for Effluents

J. M. Macdonald

B. Gomez

L. Trujillo

J. E. Malcom

H. Nekimken

N. Pope

R. Bibeau 


\section{CONTENTS}

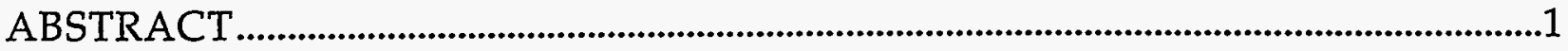

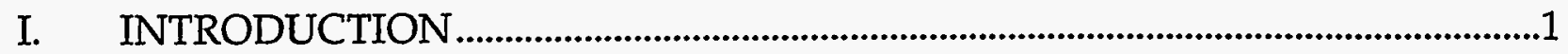

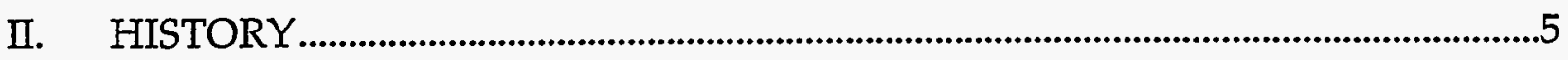

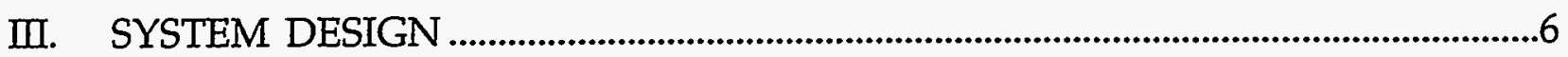

A. Methods........................................................................................................................6

B. Hardware and Software ...................................................................................................9

C. Phase Implementation ...........................................................................................13

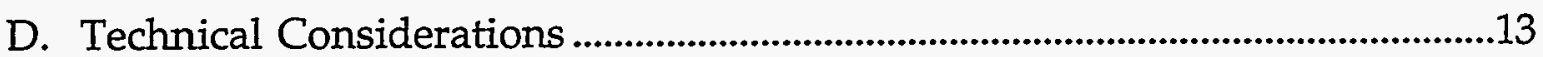

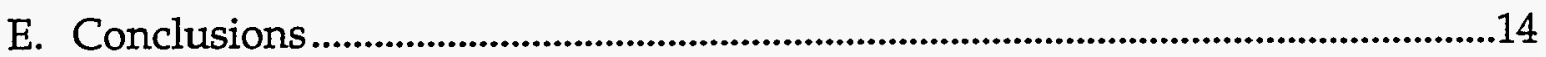

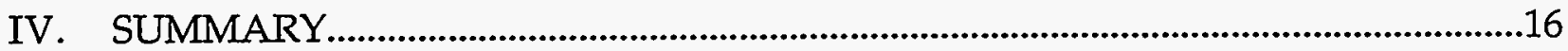

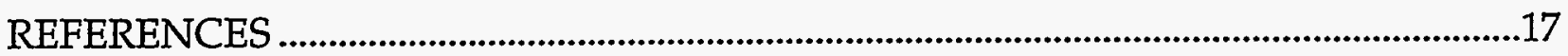

APPENDIX A: INSTRUMENTATION AND EQUIPMENT LIST ............................19

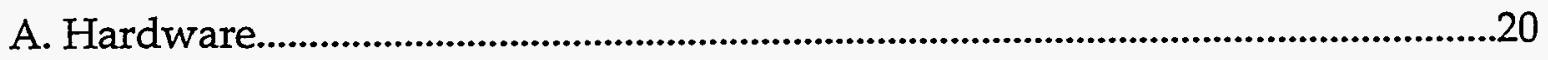

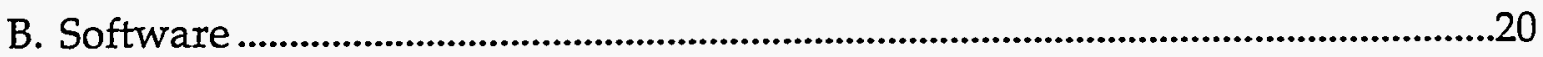

APPENDIX B: $\quad$ TRENDING SCREEN EXAMPLES........................................................23

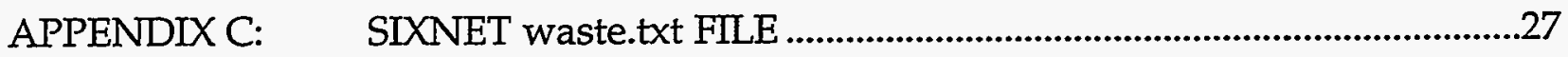

APPENDIX D: $\quad$ LSO CONFIGURATION waste.cfg FILE................................................31 
Waste Monitoring System for Effluents 


\title{
WASTE MONITORING SYSTEM FOR EFFLUENTS
}

\section{by}

\author{
J. M. Macdonald, B. Gomez, L. Trujillo, J. E. Malcom, H. Nekimken, \\ N. Pope, and R. Bibeau
}

\begin{abstract}
The waste monitoring system in use at Los Alamos National Laboratory's Plutonium Facility, TA-55, is a computer-based system that provides real-time information on industrial effluents. Remote computers monitor discharge events and data moves from one system to another via a local area network. This report describes the history, system design, summary, instrumentation list, displays, trending screens, and layout of the waste monitoring system.
\end{abstract}

\section{INTRODUCTION}

The Nuclear Materials Technology process control team at Los Alamos National Laboratory's Plutonium Facility, TA-55, has developed a waste monitoring system (WMS) for obtaining real-time information about its effluents. The WMS monitors the caustic, acid, and industrial waste pipes that leave the facility. Waste pipes are also monitored as they leave the 100, 200,300, and 400 areas of building PF-4 at TA-55. Parameters monitored in these waste lines are flow rate, temperature, and gammaradiation level. The system became functional in January 1994 and is evolving into a larger system. Major topics that this report will explore are the experiences and practical lessons learned from developing this system.

The WMS is located in the basement of TA-55 and by May 1994 had 30 point sensors that monitored temperatures, gamma radiation, and flow rates at 10 locations. Figure 1 is a computer screen display of the system showing the general locations of the sensors. Sensors are strategically placed to allow monitoring personnel to determine the points of origin of waste within the facility. Adding further sensors to the system will allow more detailed tracking of wastes. A very important attribute 
of this system is its ability to store all sensor information as computer files for historical archiving. These files provide documentation of compliance and would be useful in the event of any future audits.

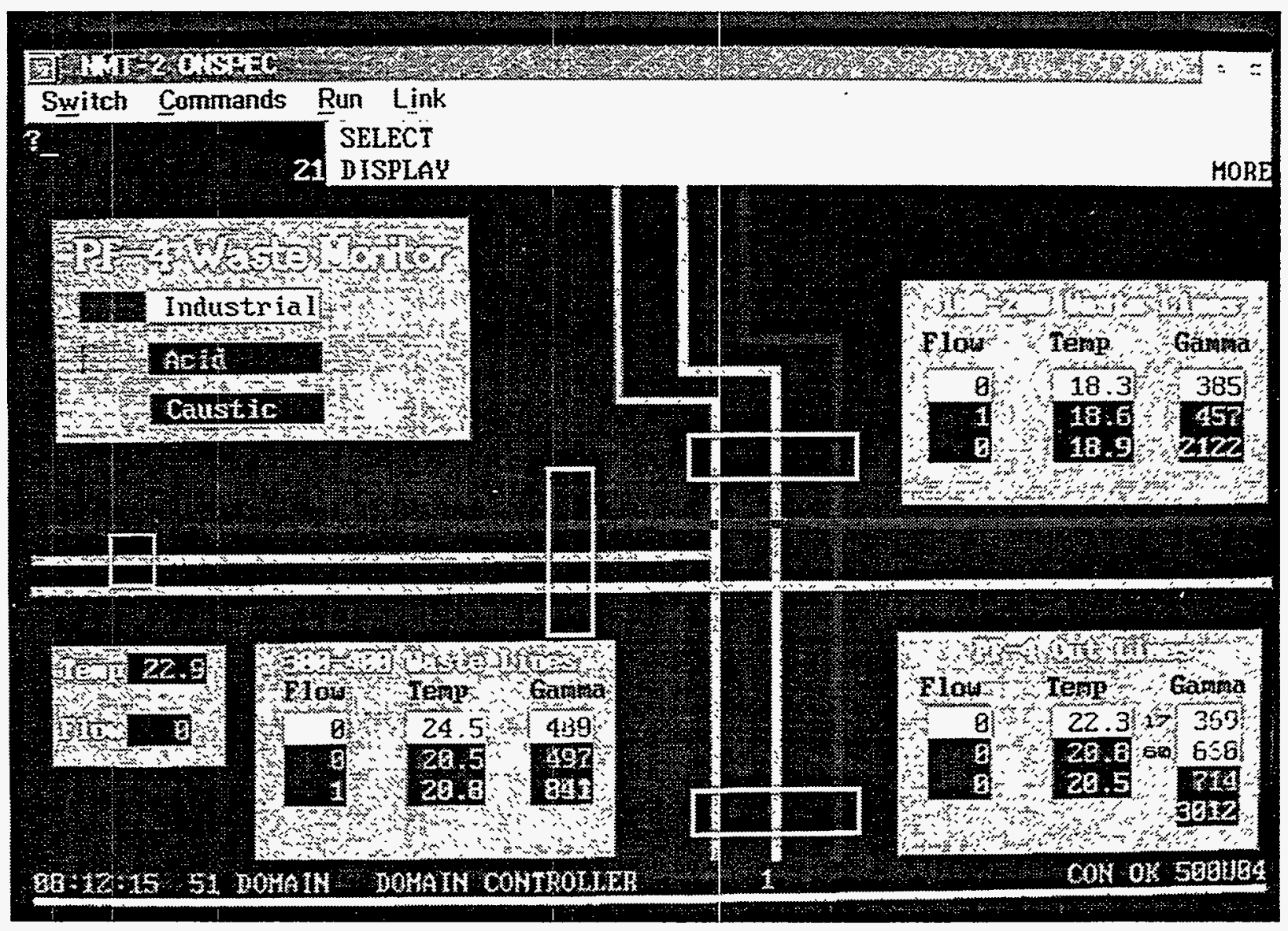

Fig. 1. WMS display screen showing sensor locations.

At the heart of the WMS is a computerized supervisory control and data acquisition (SCADA) system. The SCADA system is designed to accomplish the following three primary tasks:

1. provide an interface to WMS sensors

2. record and display data

3. distribute data to other locations via a local area network (LAN).

One benefit resulting from the WMS is the collection and storage of waste discharge information. The system monitors remote contributions to the effluent flow in real-time. The documentation of historical information (Fig. 2) allows management and users to determine the time and date a discharge occurred. This provides crucial plant management and accountability records. 


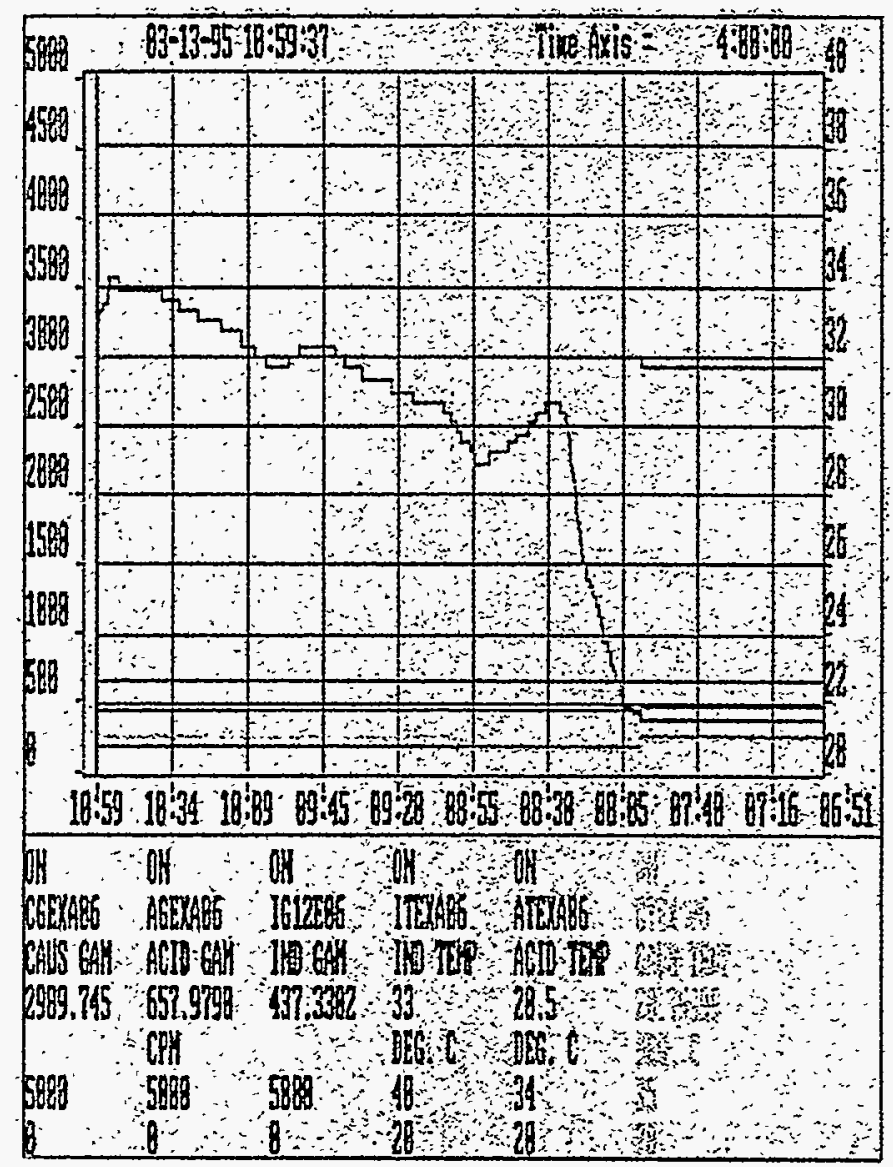

Fig. 2. Printout of effluent data, showing color-coded distributions of measured parameters with time.
Fig. 3. Computer screen display of effluent data, showing colorcoded distributions of measured parameters with time.

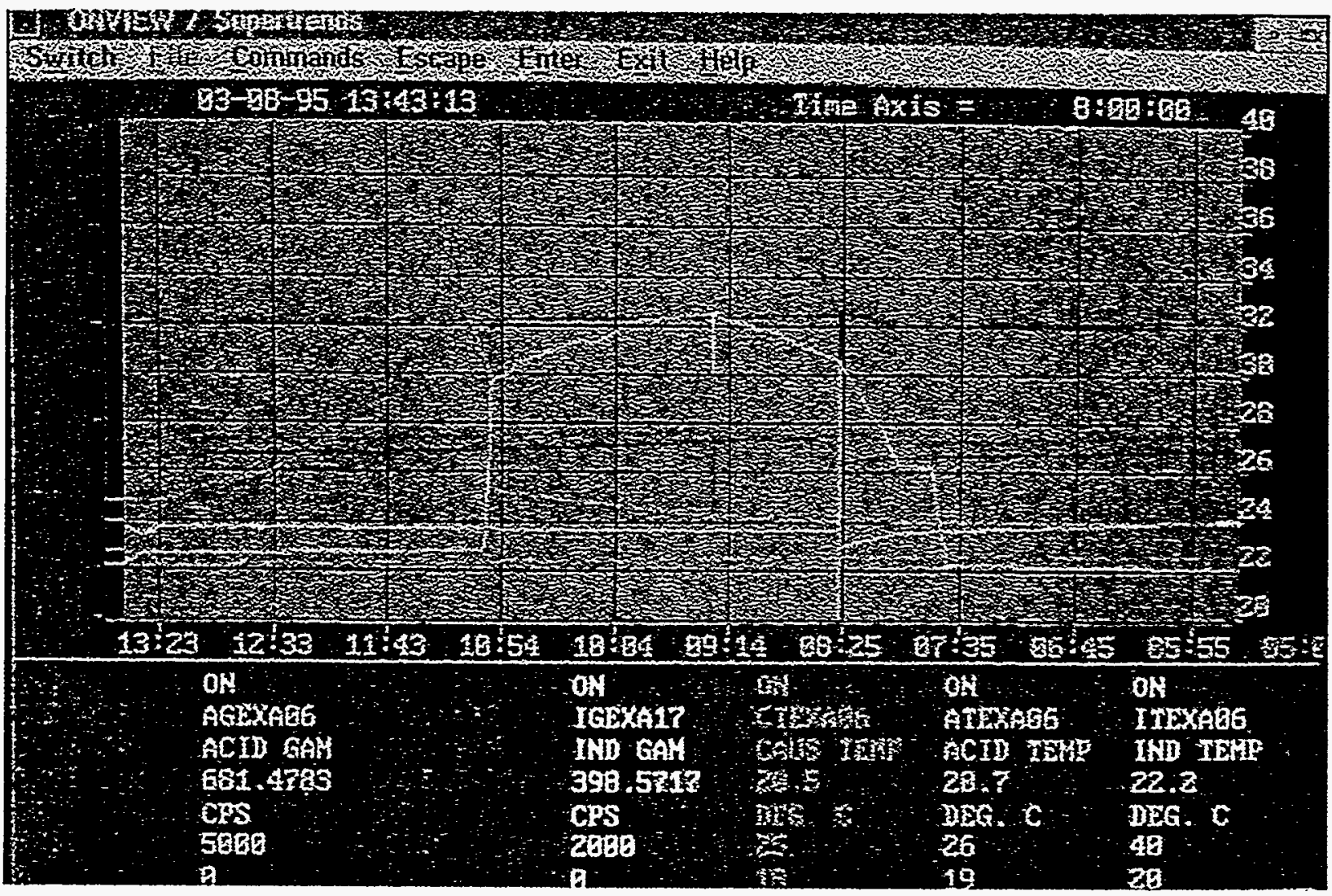


$\cdots-\infty-\cdots,-\infty$ 


\section{HISTORY}

TA-55 became operational in 1978. An internal audit conducted in September 1991 pointed out the need for developing a WMS for the facility. In 1991-92 the Nuclear Materials Processing Group for Nitrate Systems (NMT-2) spearheaded an effort to install sensors on the waste lines at TA-55. Temperature, flow, and gamma radiation were selected as the parameters that would have the highest probability of detecting a discharge. Originally, sensors passed their signals to a chart recorder for permanent historical recording. The chart recorder was located in the basement of TA-55.

Today, with the completion of the WMS, a user with a networked desktop com-' puter can monitor the sensors, the integrity of the system, and historical records of all past sensor readings, both as raw data and in graphic form. Users may perform many additional analyses of waste discharges that were impossible to perform before the installation of this system. Reliability, ease of use, and historical archiving were improved with this system, and real-time monitoring of multiple sensors was introduced. The present WMS eliminates paper chart recording and supports sitewide efforts toward a paperless work environment. 


\section{SYSTEM DESIGN}

\section{A. Methods}

The nucleus of the WMS is a SCADA system computer (Fig. 4) that executes commercial human/machine interface (HMI) software. The HMI software interacts with a Digitronics SIXNET I/O data acquisition and control system. Gamma radiation sensor signals are collected in the instrumentation in the secondary rack that houses data collecting equipment.

The SCADA HMI also provides an interface between the system hardware and the user. A commercial HMI software package is used on an IBM personal computer that uses an Intel 80486 central processing unit and the OS/2 2.1 operating system. The real-time process parameters displayed are of gamma radiation, flow rate, and temperature. Data are periodically archived to computer disks and backup tapes. The OS/2 2.1 multitasking computer operating system simplifies configuration tasks because different computer operations can be performed simultaneously. The SIXNET data acquisition and control system collects signals at two junction boxes (Fig. 5) from flow sensors, gamma radiation sensors, and type-J thermocouples.

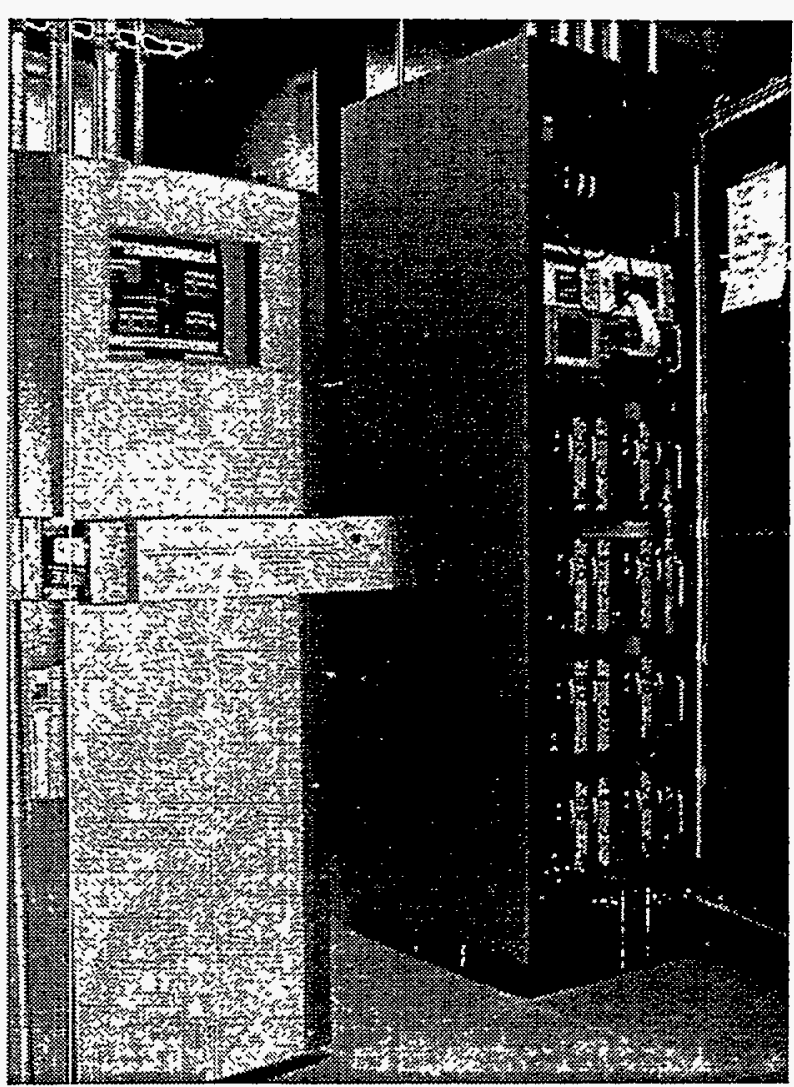

Fig. 4. The SCADA system computer (with the gamma rack in the background).

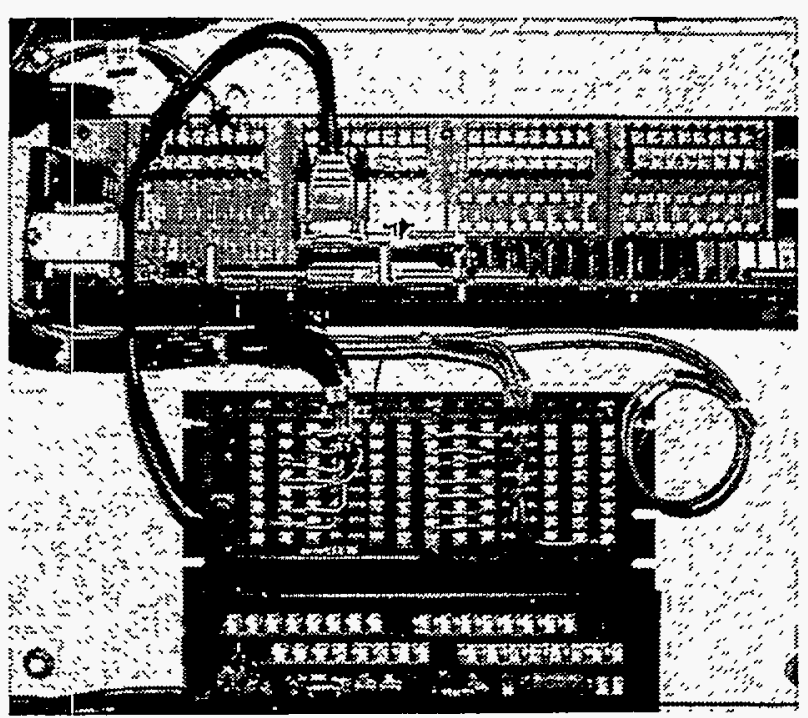

Fig. 5. One of two junction boxes for collection of signals from the sensors. 
Sixty-four channels of input are presently available in the system. Thirty channels are currently used to collect signals from the sensors (Figs. 6 and 7), leaving thirty-four channels unused. These unused channels will allow future growth of the system.

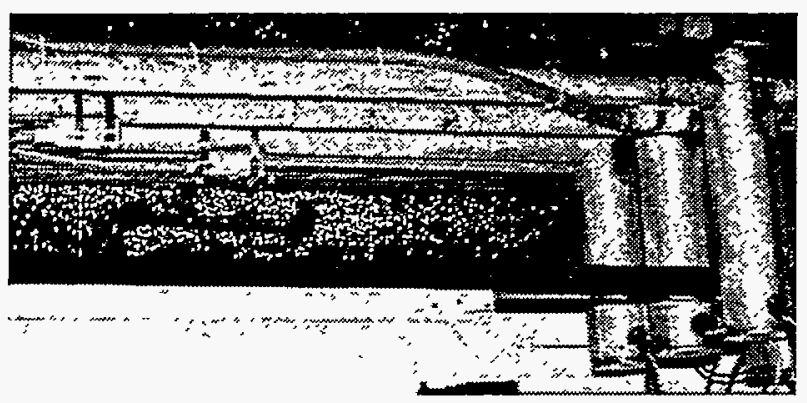

Fig. 6. Three flow sensors and three gamma radiation sensors. The gamma sensors hang from the pipes to the right; the flow sensors are the smaller units strapped to the pipes.

Currently, the WMS is only capturing and archiving sensor data. In the near future, an expansion of capabilities to allow grab-sampling of waste streams is envisioned. Valves would be controlled with the HMI software.

The WMS has the capability to set up alarms for discharge events. The developer or user can set up alarms that perform certain functions (such as dial a personal pager or close valves) and emit audible warnings at remote computers running the HMI software.

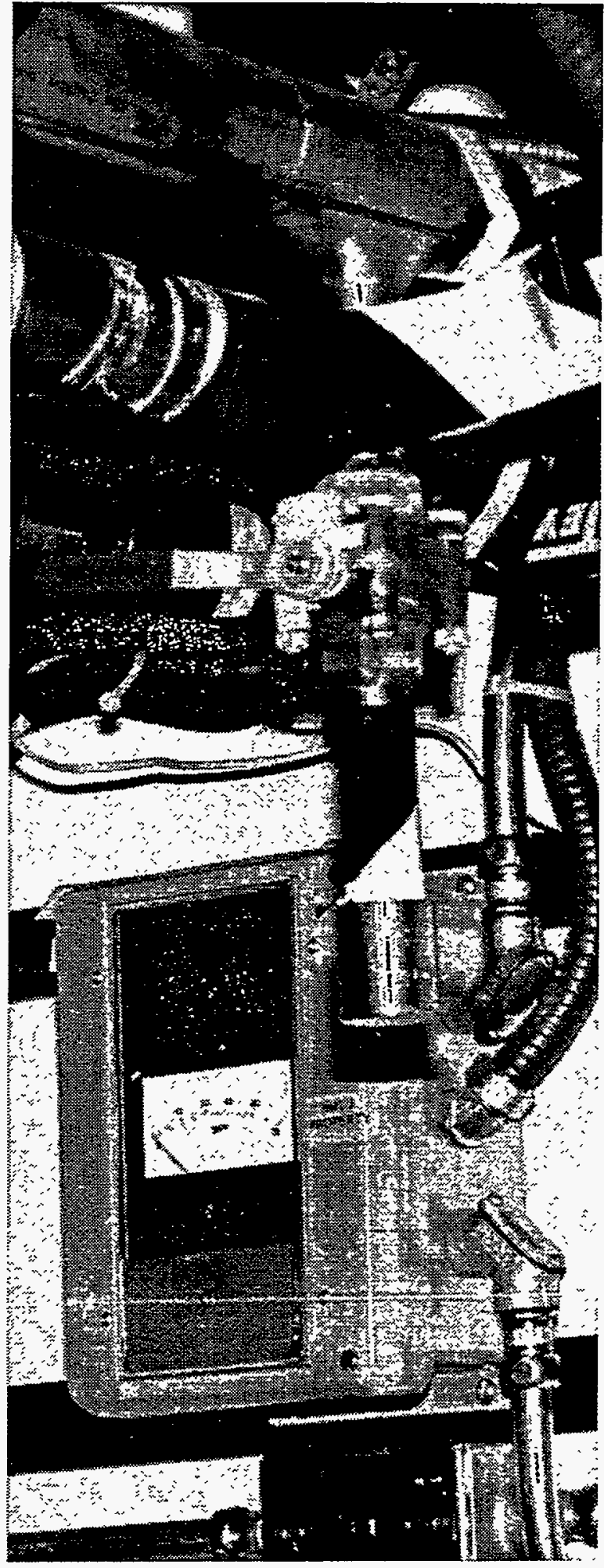

Fig. 7. A type-J thermocouple lies against a pipe at the top of this figure, which also shows a flow totalizer and one of the valves that might be automatically controlled in future versions of the WMS. 
Engineering challenges to the TA-55 WMS included the exposure of the SCADA system to the vibration, dust, and hazards of an industrial situation. One extreme problem faced by people in the basement of TA-55 is the high ambient noise level; hearing protection must always be worn when working there. The SCADA system is housed in an environmental protection rack that is bolted to the basement floor to protect the system if an earthquake should occur. Cooling of the SCADA system rack has not been required, but in another system located in the same facility, computer displays have malfunctioned, probably as a result of heat stress.

Data collected by the SCADA computer are transferred to other computers via an Ethernet LAN. The Large System Onnet (LSO) program from Heuristics transports information stored in the HMI internal database and allows any other computer running the same software to receive the data. Live process data are viewed using the same formatted HMI displays across the network (Figs. 1, 10, and 11 are examples of these displays). The option exists for users to customize their displays, but the maintenance involved in supporting multiple computers using different displays can rapidly become prohibitive. In the TA-55 WMS we recommended using the standard display screens, but we encouraged users to modify the trending screens to allow them to view the process information in the form that best suits their needs. Appendix B and Fig. 3 show examples of the available trending screens.

Fig. 8 is a system block diagram that shows the various components of the TA-55 WMS.

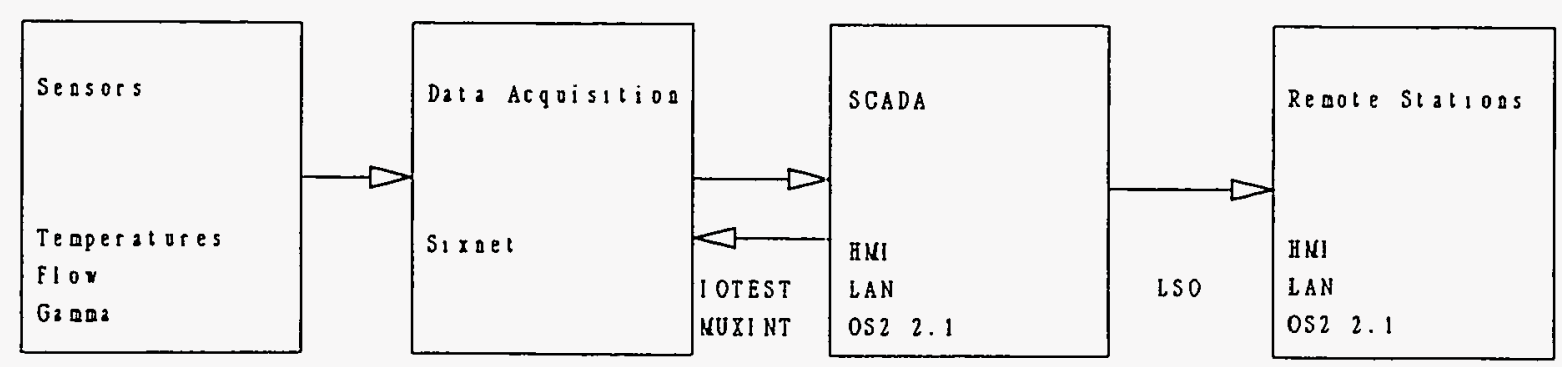

Fig. 8. System block diagram arrows indicate data flow. 
The fundamental components of the system are the temperature, flow, and gamma radiation sensors, which collect readings that are forwarded to the SIXNET I/O data acquisition and control system. IOTEST and MUXINT are software used to configure SIXNET. The data from the sensors are then directed to the SCADA system, which converts the data to engineering units and stores them as a computer file. ONSPEC is the HMI software and the main controlling software on the SCADA node. The SCADA computer can also download configuration programs to the data acquisition system. Through the LAN, remote monitoring stations are able to access the information contained on the SCADA node and can receive updates across the network as often as every second.

\section{B. Hardware and Software}

The following sensors were selected for the WMS:

1. Type-J surface-mount thermocouple temperature sensors that indicate chiller or steam activities in the plant,

2. 4-20-mA ultrasonic flow sensors that indicate discharge activities, and

3. $0-10-\mathrm{Vdc} \mathrm{NaI}$ sensors that detect gamma radiation from radionuclides.

Data are acquired through the two networked SIXNET I/O hardware devices, which have all sensors connected to them. The Digitronics SIXNET system is a general data acquisition tool configured to accept several signal protocols, including 0-5 $\mathrm{Vdc}, 4-20 \mathrm{~mA}, 0-10 \mathrm{Vdc}$, and $120 \mathrm{Vac}$. Up to 64 separate analog signals can be collected. The types and ranges of the signals are user-selected by switch settings or through software. SIXNET remote units communicate with a coprocessor adapter in the computer by a simple two-wire network link.

The SIXNET hardware configuration programs IOTEST and MUXINT reside on the SCADA computer and are used to configure the SIXNET data acquisition system. These programs are used at system start-up and for troubleshooting diagnostics of the SIXNET system. The menu-driven utility IOTEST starts SIXNET each time a user powers up the system. IOTEST can also be used to quickly determine if the user is receiving data from the sensors. A second software utility, MUXINT, is used to configure the 60-IOMUX data collection units, which are part of the SLXNET system.

Data sent to the computer from SDXNET are converted into a format that the HMI software can use through a separate program (the device I/O driver). The algorithm to convert the data into a particular range or engineering unit resides in a text 
file that can be modified as required. Additional configuration information about the hardware and the timing of the data acquisition are also stored in this file. A sample file, waste.txt, can be found in Appendix C. The device I/O driver converts the raw data into standard engineering units and places the information into the HMI internal database.

The HMI internal database resides in the volatile memory of the computer. The person configuring the database usually associates a tag name with the value received from SIXNET. This provides easy reference to the data points. For example, EUR400 from SIXNET is given a tag name of $A_{\mathrm{A}}$ T34D11 in the HMI software. An acid temperature sensor, on the 300/400 waste line, located at column D11 in the basement, is called AT34D11. An eighth character position exists for the reference signal that is used in gamma-sensor calibrations. Figure 9 shows a breakout example of this tag name.

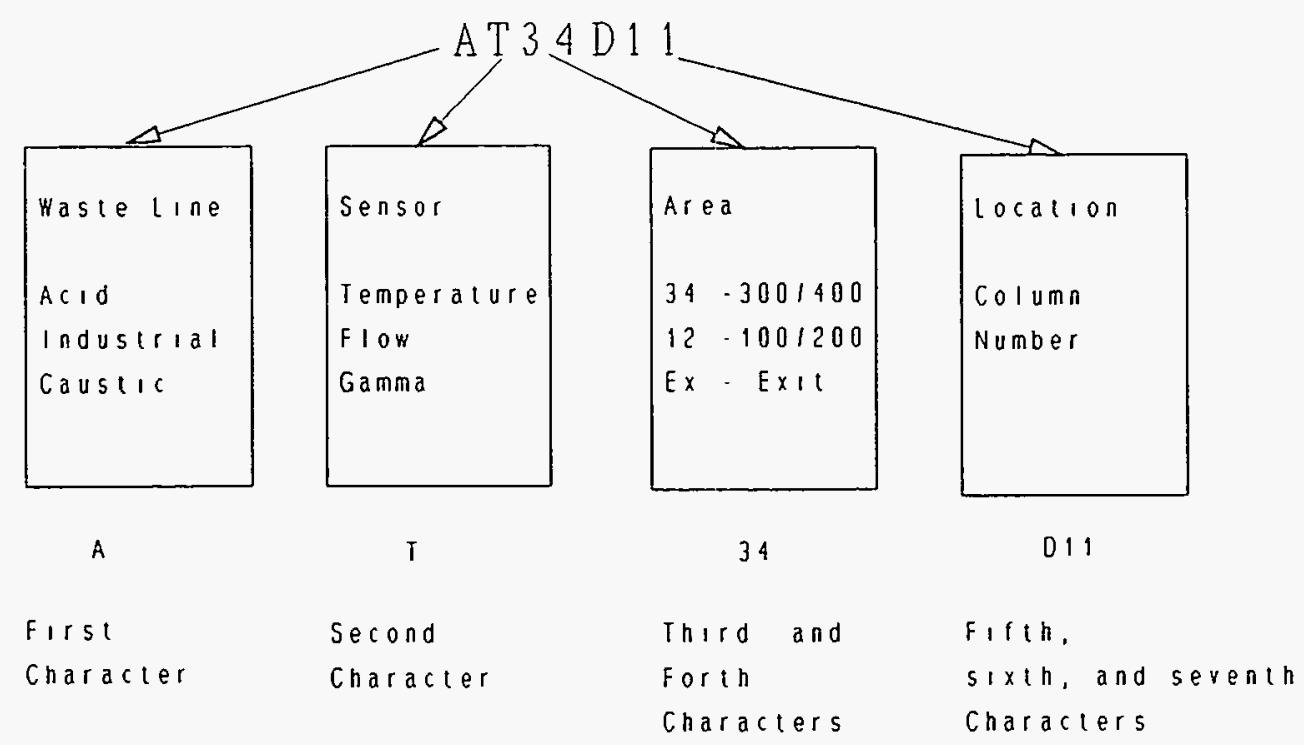

Fig. 9. Tag name breakout example.

It is extremely important to reserve a block of parametric numbers for the automation of multiple processes, and it is recommended that the developer clearly assign a specific range of values to this particular process. In the WMS, all engineering units real (EUR) HMI data table values are assigned numbers in the range from 400 to 599 as indicated in the waste.txt file in Appendix C. This approach is highly desirable, especially if there are additional processes that will be running on the remote systems. Conflicts and confusion would certainly arise if these same EUR numbers were used by another process. 
Displays 32 and 33 (Figs. 10 and 11) are diagnostic screens that quickly summarize the sensor readings. These two screens were more heavily relied upon when the system was first installed. They are still used today to provide a quick cross-reference between tag names and I/O driver values.

\begin{tabular}{|c|c|c|c|}
\hline \multicolumn{4}{|c|}{ 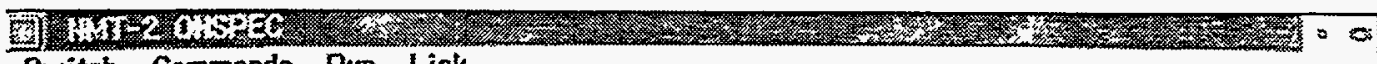 } \\
\hline \multirow{3}{*}{\multicolumn{4}{|c|}{$\begin{array}{l}\text { Switch Commands } \frac{\text { Run Link }}{1 \text { SELECT }} \\
\text { 32 DISPLAY }\end{array}$}} \\
\hline & & & \\
\hline & & & \\
\hline EuRde日 arsan14 & EUMS98 $\times 1 \times 8 \times \times x$ & EIM416 & EUR424 \\
\hline 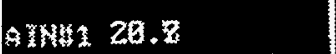 & Antwe 17.5 & Ama 301 fLow 82 & 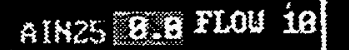 \\
\hline 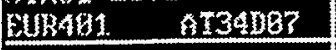 & EURAG9 $\quad \times 1 \times \times \times \times x$ & EuR417 & $x \times x \times x \times x$ \\
\hline 维2 25.3 & AlW10 1r.4 & คIN16 & AINas Daf FLo: 11 \\
\hline Imsulag? & $x \times x \times x x$ & EUR418 IF34DA? & PU1MA26 XFXXX8X \\
\hline Anes $22 . ?$ & alvit 17.4 & OMNa 84 mon 84 & AIVZ7 KIA FLOH 12 \\
\hline Cr3400? & EInf11 & Euncis & DunA27 \\
\hline 8 & 17.3 & 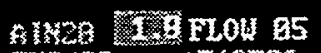 & 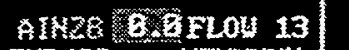 \\
\hline culnags & EUI & Dumarg af & \\
\hline 83 & 17.6 & AWE & nlmes 00 \\
\hline Iy & Eving13 & & \\
\hline & 7.4 & $8 ?$ & 3Ya spare \\
\hline crr1znot & EUM414 & & EUR4: \\
\hline 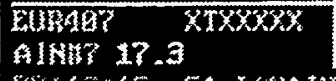 & $\begin{array}{l}\text { EuR415 } \times T X X X X X \\
\text { AlW15 } 17.4\end{array}$ & 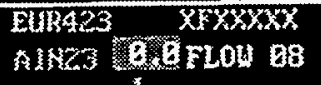 & Alwat 2121 \\
\hline & & & \\
\hline
\end{tabular}

Fig. 10. Display screen 32.

\begin{tabular}{|c|c|c|c|}
\hline \multicolumn{4}{|c|}{ 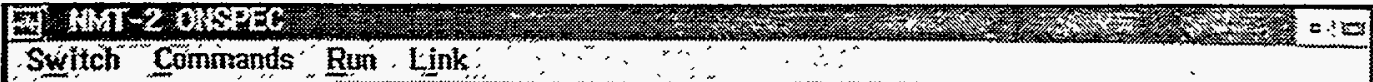 } \\
\hline ? & $\begin{array}{l}\text { SELECT } \\
\text { DISPLAY }\end{array}$ & & 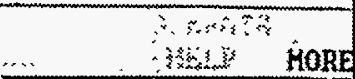 \\
\hline 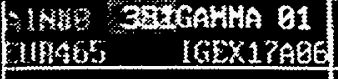 & 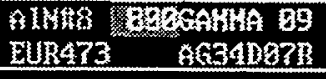 & 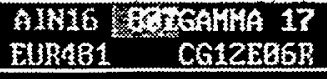 & 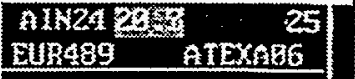 \\
\hline 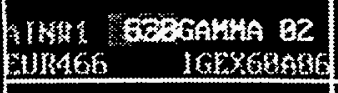 & 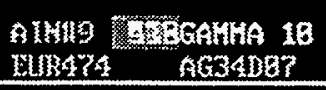 & 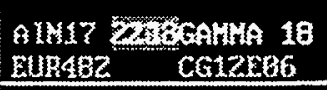 & A IN25 2 E \\
\hline 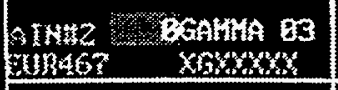 & 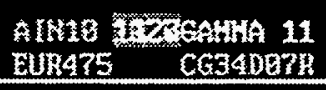 & 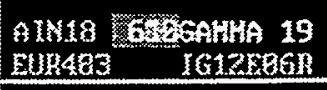 & AlH26 ar $\quad$ A 27 \\
\hline 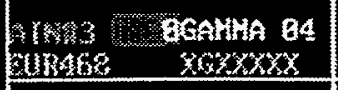 & 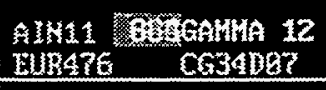 & 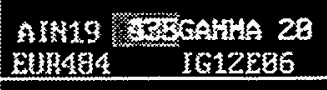 & 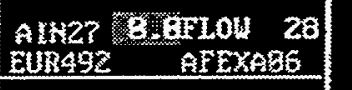 \\
\hline 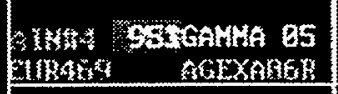 & 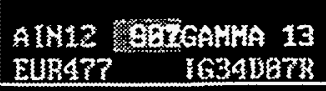 & $\begin{array}{l}\text { A mag } \\
\text { Bursas }\end{array}$ & 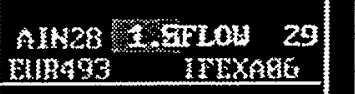 \\
\hline 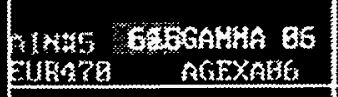 & 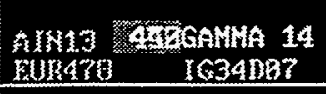 & 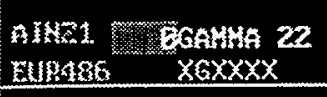 & 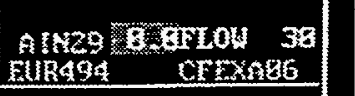 \\
\hline 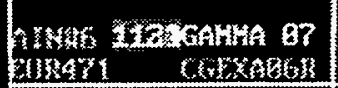 & 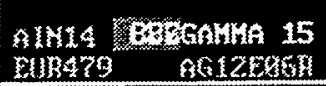 & 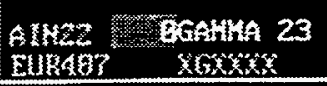 & $\begin{array}{l}\text { AnOa } 20 \text {. } \\
\text { DuR495 }\end{array}$ \\
\hline 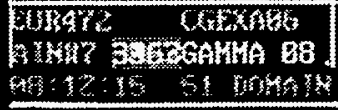 & 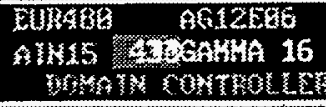 & 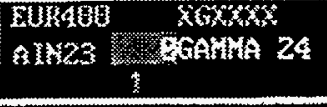 & 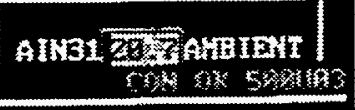 \\
\hline
\end{tabular}

Fig. 11. Display screen 33. 
The HMI software ONSPEC provides an effective presentation of data from the system sensors via its display screens. Historical data trends from the sensor data are developed and maintained by the HMI software as well. The HMI software also saves data in a binary file format. The files can be saved in daily, weekly, monthly, quarterly, or yearly formats. The WMS uses a monthly file format, and files are stored in the SCADA computer history directory. EUR400M.005 is an example of the EUR400 historical monthly file for May. The monthly data can be exported to other software for evaluation and graphing (see Fig. 2 and Appendix B; note the correlation between temperature and flow-data sets in Fig. 2).

The LSO software module from Heuristics provides swift, accurate, and reliable transfer of the internal database values to other computers on the network. A text configuration file similar to that used for SIXNET is also used with LSO. An example of this file is found in Appendix D. Note that the EUR value ranges from 400 to 599 in this file; this indicates a block move of internal database values across the network.

The WMS is running on a network of over 300 computers. To obtain updates of sensor data at one-second intervals through a remote computer requires considerable network computational resources. We used a network analyzer to determine how the WMS impacts the network. The network analyzer provided information on total network communications and individual machine communication profiles. Of the 10 computers that transfer the greatest quantities of data on the network, 8 are typically used for process control. The network analyzer also identified a possibly critical future problem if additional remote nodes were added to this network. Performance of the total network could degrade, and users might be encumbered by a slow response time. To solve this problem could be costly if expensive hardware were necessary to increase the network communication throughput. 


\section{Phase Implementation}

The WMS was implemented using a phased implementation approach. The system was tested as extensively as possible in a prototype laboratory before installation. The following tests were conducted in this laboratory:

1. sensors were tested to ensure correct operation

2. the data acquisition system was placed on the network and tested to ensure correct functioning of equipment

3. HMI display and trend screens were created, modified, and approved by users

4. extensive testing and evaluation of the complete system were performed.

When the system was brought on-line for the first time in the final location, it was very easy to troubleshoot problems. Single components of the system were started up one at a time. The second SIXNET data acquisition system was brought on-line only after the first system was operating properly. All sensors were brought on-line in a systematically through the data acquisition system. The result of this phased implementation was a speedy and successful installation of the system.

\section{Technical Considerations}

Nonintrusive sensors were used for the WMS. All sensors were externally attached to the pipes (Figs. 6 and 7).

The pipe sizes are as follows:

$$
\begin{array}{ll}
\text { industrial - } & 2.0 \text {-in. } \\
\text { caustic - } & 1.5-\text { in. } \\
\text { acid - } & 1.5-\text { in. }
\end{array}
$$

SIXNET recommends a Belden Datalene cable \#9182 (which is designed for highspeed data transmission in network communication) between the 60-IBM/N adapter and the IOMUX-RUT board on the 60-IOMUX-FEB. A substitute cable description can be found on page 15 of the 60-IBM/N SLXNET Network Co-Processor technical manual.

$\mathrm{J}$-type versus $\mathrm{K}$-type thermocouple evaluations were based primarily on data sensitivity requirements. Because large ranges of temperature data were not expected, $\mathrm{K}$ type thermocouples were not installed in the system. 


\section{E. Conclusions}

The WMS uses a multitasking operating system in the SCADA and remote nodes. This facilitates developing and accomplishing various concurrent jobs on a single computer system. Major issues to consider are whether drivers for the data acquisition system exist and whether other drivers are available for the selected operating system.

An important consideration is the expected lifetime of the sensors. The expected length of time that sensors typically function must be known in order to estimate the cost of operating the system; this information is usually difficult to obtain.

When installing the WMS in the basement of TA-55, the most common problem was crossed wires. This is a common problem when installing new wires in any project.

A program needs to be developed that tests the sensors and the data acquisition system to ensure the entire system is operating within prescribed parameters. Sensor tagging helps maintenance personnel to easily locate and troubleshoot the system sensors.

Calibration of sensors can be challenging. Attempts to calibrate flow sensors in the system proved to be problematic, because discharging known amounts of water created a waste discharge. Coordinating the discharge observed by a sensor with the actual amount discharged proved difficult. An approach now under consideration is the use of a portable calibrated flow sensor, which would be placed adjacent to the current sensor in the system. The local sensors could then be adjusted to match the reading from the portable calibrated sensor.

The Bicron gamma radiation detectors are seeded with alpha activation methods. This gives a gamma energy peak in the nominal energy region of $800 \mathrm{keV}$ to $1.4 \mathrm{MeV}$. with a count rate of $1000 \mathrm{cps}$. The signal channel analyzer (SCA) in the Harshaw amplifier is adjusted so that the counts within this energy region are registered on the first ratemeter. This count is used as an indicator that the electronics are functioning correctly. The analog recorder output of the ratemeter is cabled over to the IOMUX I/O multiplexing unit. These reference signal data are displayed for the operator and archived to computer files.

The model 2030 SCA is adjusted to span a region (from $50 \mathrm{keV}$ to a user-defined upper limit) that would be observed from material that could be present in the waste line. Counts in this region are registered on the second 661 ratemeter in the system and the analog output is taken to the multiplexing unit for system monitoring and display. 
The initial sensor adjustments were made using appropriate standards that were placed between the waste lines and the detector face. Periodic checks of the accuracy of the system can be made using these standards.

Deadbands are sensor-change delta values that indicate areas of interest that are stored to a historical file. For example, if a temperature probe deadband is set to $1^{\circ} \mathrm{C}$, then only when the temperature changes by $1^{\circ} \mathrm{C}$ will a new value be written to a file. This reduces the size of the historical data file. Setting deadbands for the sensors requires a thorough knowledge of the potential data points. The system sensors should be monitored closely during the initial start-up of the system to determine what deadbands are needed, and plenty of time should be set aside for setting deadbands in a new system. Deadbands were set and optimized over a three-week period for the TA-55 WMS.

Precautions against power outages and lightning should be incorporated into the system with surge protectors and uninterruptible power supplies. The system should also be tested for its ability to come back on-line after an interruption in power. The TA-55 WMS has responded well to scheduled and unscheduled power outages; the system is able to recover and collect data following an outage.

A backup and redundancy strategy should be implemented for optimal operation of the system. Backups of computer system files and historical files are saved to tape. A second industrial IBM computer is loaded with the required software and can assume the role of the SCADA computer in a short time if the main SCADA computer fails. 


\section{SUMMARY}

A feature currently under evaluation for inclusion in the WMS is the ability to quantitatively determine what chemicals (such as nitrates or metals) are leaving the plant. Determination of total volumes of discharges and the maintenance of accurate online records in the system are additional areas for development. Control of the timing and nature of waste discharges from the plant can easily be incorporated into this system by installing remotely activated control valves on the pipes (Fig. 7). We expect to expand capabilities and to add more sensors to improve the tracking of waste origination. Testing of new thermocouples for possible inclusion in the system is underway.

The new WMS at TA-55 is a quantum leap forward from its predecessor, the chart recording system. The WMS provides much more information and introduces real-time monitoring capabilities. Its remote monitoring capability provides greater safety and convenience for users and management. Since the system came on-line, it has shown itself several times to be unprecedentedly useful in tracking waste discharges. 


\section{REFERENCES}

The following companies provided information for this report:

Intel Corporation, P. O. Box 58119, Santa Clara, CA 95052-8119

Heuristics, 9845 Horn road, Sacramento, CA 95827

International Business Machines, Armonk, NY 10504

Digitronics SIXNET, P. O. Box 767, Clifton park, NY 12065

Canberra Industries, Inc., 800 Research Parkway, Meriden, CT 06450

Omega Engineering Inc., P. O. Box 4047, Stanford, CT 06907-0047. 
Waste Monitoring System for Effluents 
Appendix A: Instrumentation and Equipment List

\section{Appendix A}

Instrumentation and Equipment List 


\section{INSTRUMENTATION AND EQUIPMENT LIST}

\section{A. Hardware}

The following hardware items are used in the WMS.

Computer. Model Value Point 486 DX2 with 16 MB RAM, VGA graphics, 3.5-in. floppy drive, $200 \mathrm{MB}$ hard drive, keyboard, color monitor, International Business Machines Corporation, Armonk, NY 10504.

Backup Computer. Model 7537486 SX with 16 MB RAM, math coprocessor, VGA graphics, 3.5-in. floppy drive, $500 \mathrm{MB}$ hard drive, keyboard, 7544 color monitor, International Business Machines Corporation, Armonk, NY 10504.

Data Acquisition System. The system consists of several individual components, including the model 60-IOMUX I/O multiplexing unit, the model 6-IO32 discrete I/O unit, the model 60-AMI analog multiplexor interface, a 60-MPLEX analog input multiplexor, and a model 6MT cable. Digitronics SIXNET, Clifton Park, NY.

Flow Sensor. FD-302, indicator, transmitter ultrasonic flowmeter. Omega Engineering, Inc., P. O. Box 2284, Stamford, CT 06906.

Type-J Thermocouples. Iron-Constantan 304 SS Sheath 1/8-in., 12-in. length. Omega Engineering, Inc., P. O. Box 2284, Stamford, CT 06906.

Gamma Sensors. Model Bicron 2m2/2-AM-241-X, 2-in. sodium-iodide thalliumdoped with, B50B01-4 photomultiplier tubes, and a Canberra photomultiplier-tube base-preamplifier model 2007P.

Scada Environmental Rack. Model PC 4610 version 2. Rittal, 3100 Upper Valley Pike, Springfield, $\mathrm{OH}$.

Gamma Rack and Equipment List. The system consists of several individual components. Each detector has a Canberra model 3102D power supply, Harshaw model NA-23 stabilized AMP/SCA, Canberra model 2030 single channel analyzer, and two EG\&G Ortec model 661 ratemeters.

\section{B. Software}

The following software items are used in the WMS.

Operating System. OS/2 version 2.1 International Business Machines Corporation, Armonk, NY 10504. 
HMI Software. ONSPEC 4000 Control Software 2.10, ONSPEC

Digitronics SIXNET I/O driver, OnView with Supertrends electronic trend pen recorder, Large System ONNET version 2.56. Heuristics, Inc., Sacramento, CA 95827.

Network Software. LAN Server or Requestor version 2.10. International Business Machines Corporation, Armonk, NY 10504.

IOMUX and MUXINT, SIXNET configuration software. Digitronics SIXNET, Clifton Park, NY. 
Waste Monitoring System for Effluents 
Appendix B: Trending Screen Examples

Appendix B

Trending Screen Examples 


\section{TRENDING SCREEN EXAMPLES}

Trending screens are used extensively in the WMS. The displays give a historical perspective of the sensor selected for trending. A maximum of 14 points can be plotted simultaneously on the same screen. These two pages provide examples of printouts of trending screens used in the WMS. Figures 2 and 3 provide color examples of both hard-copy printout and actual monitor images of trending screens.

\section{February 1,1995 Temperature Plots}

Deg. C

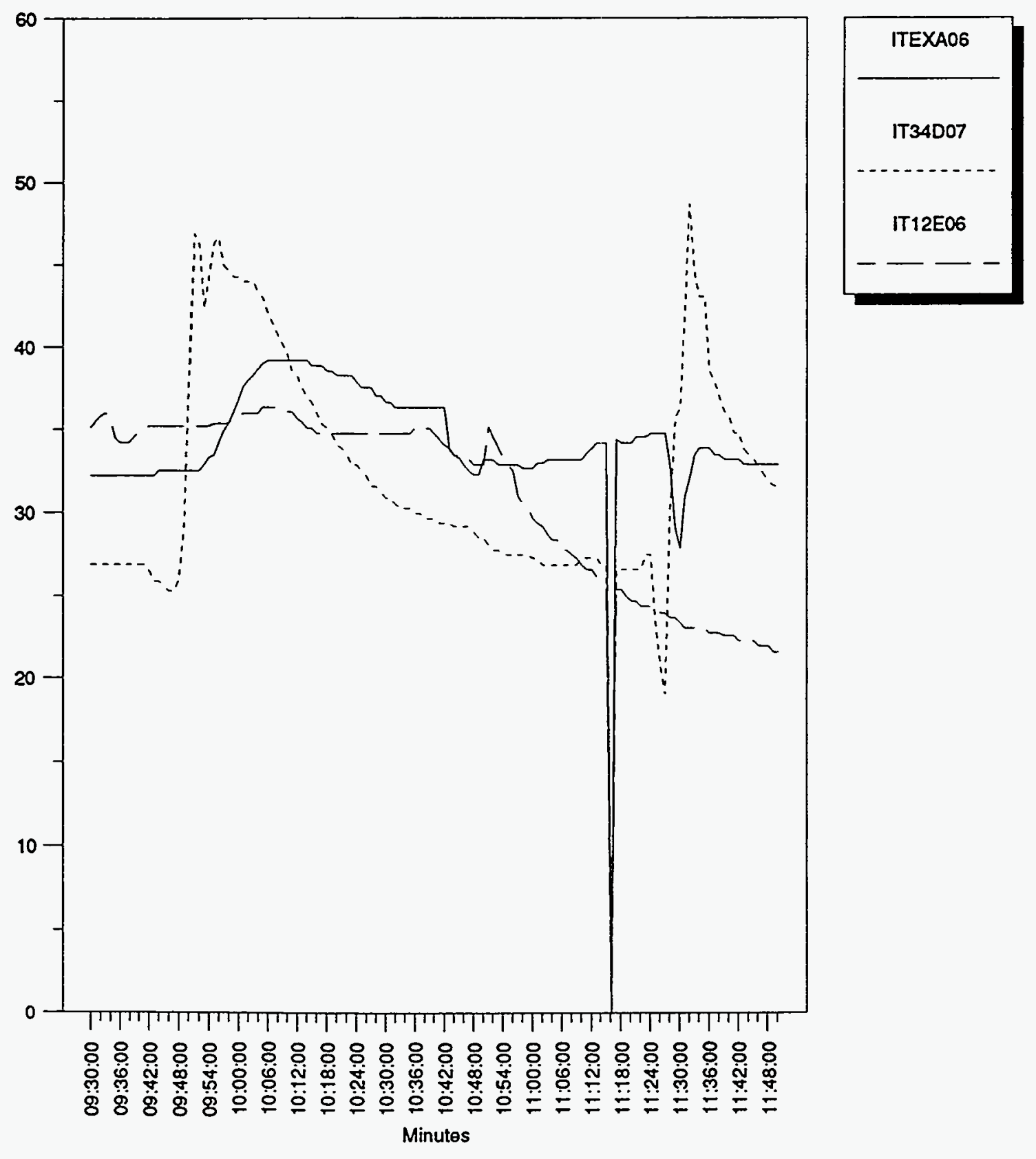


Industrial line summary for January 1994

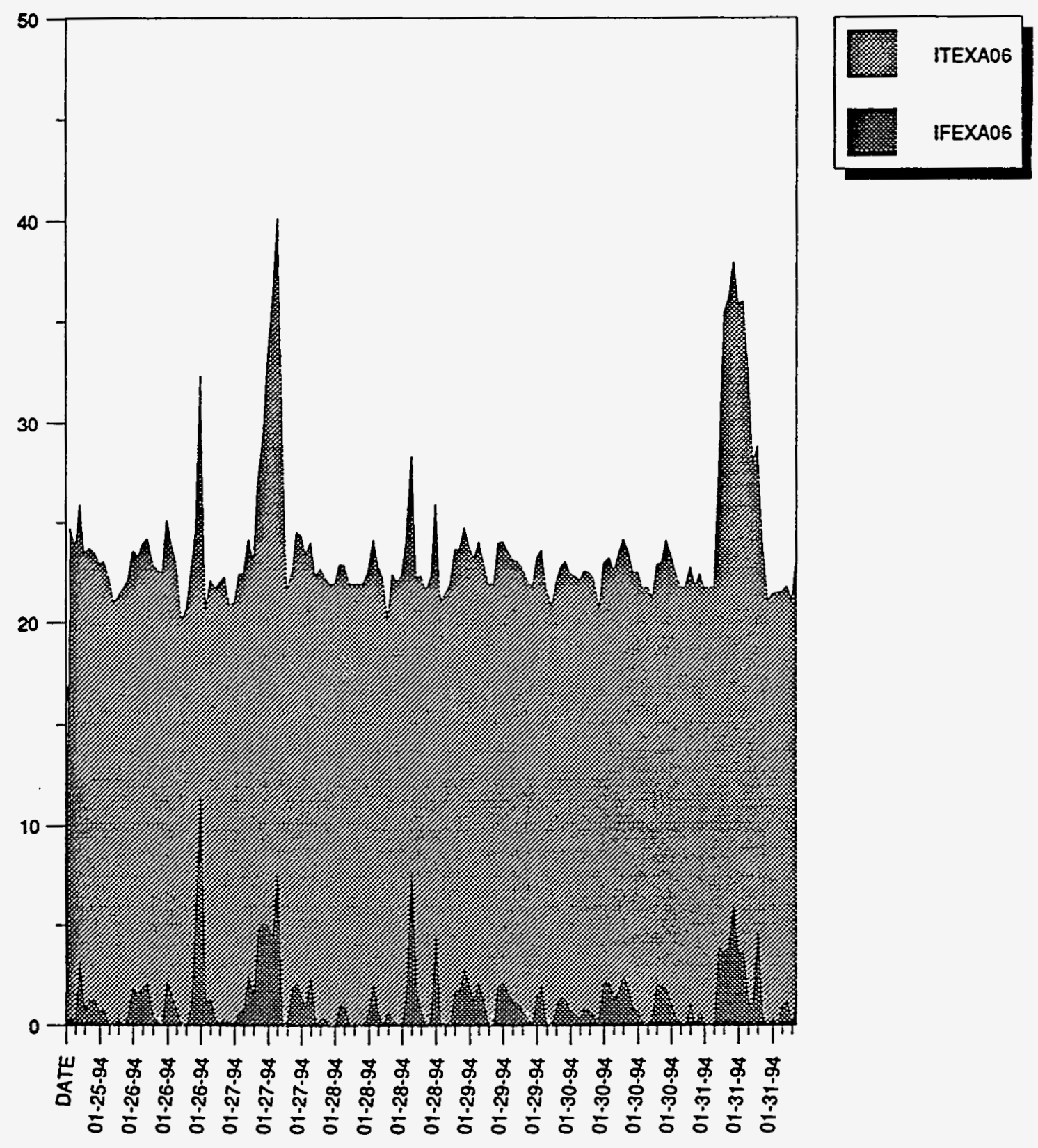


Waste Monitoring System for Effluents 
Appendix C: SIXNET waste.txt File

Appendix C

SIXNET waste.txt File 
Waste Monitoring System for Effluents

\section{SIXNET waste.txt File}

The following is the SIXNET waste.txt file:

\section{; CONFIGURATION FILE FOR THE DIGITRONICS SIXNET I/O DRIVER.}

;

DELAY $=10$

;

;CYCLE COMMAND ADDRESS START-ID END-ID

CONV V1 V2

$1 \quad$ DIN 00 DII[400] DII[407]

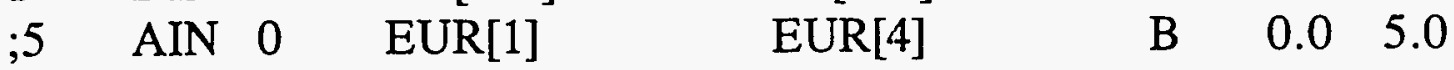

PF-3 BASEMENT JUCTION BOX \#1 60-MPLEX-32 ISOLATED ANALOG INPUTS

5

5

5

5

\section{5}

AIN 00

$\operatorname{EUR}(400) * \mathrm{~L} \quad 00.1$ AIN 01 $\operatorname{EUR}(401) * \mathrm{~L} \quad 00.1$ AIN 02 $\operatorname{EUR}(402) * \mathrm{~L} \quad 00.1$ AIN 03 $\operatorname{EUR}(403) * \mathrm{~L} \quad 0 \quad 0.1$ AIN 04 EUR(404) * L $\quad 00.1$ AIN 05 $\operatorname{EUR}(405) * \mathrm{~L} \quad 00.1$ AIN 06 EUR(406) * L 00.1 AIN 07 $\operatorname{EUR}(407) * \mathrm{~L} \quad 00.1$

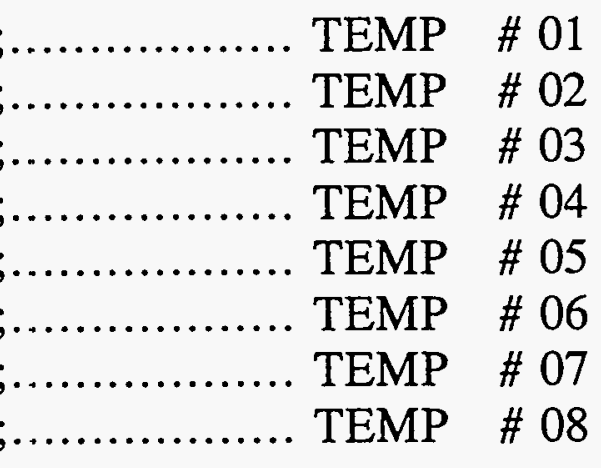

$\begin{array}{llllllll}\text { AIN } & 08 & \operatorname{EUR}(408) * \mathrm{~L} & 0 & 0.1\end{array}$

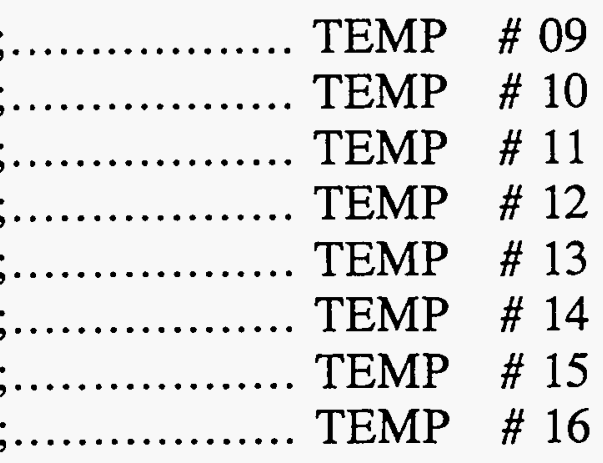

AIN $16 \quad \operatorname{EUR}(416) * \mathrm{~B} \quad 0 \quad 100$ FLOW \# 17 AIN $09 \quad \operatorname{EUR}(409) *$ L 00.1 AIN $10 \quad \operatorname{EUR}(410) * \mathrm{~L} \quad 00.1$ AIN $11 \quad$ EUR(411) * L 00.1 AIN $12 \quad \operatorname{EUR}(412) *$ L 00.1 AIN 13 $\operatorname{EUR}(413) * \mathrm{~L} \quad 00.1$ AIN $14 \quad$ EUR(414) * L 00.1

$\begin{array}{llllll}5 & \text { AIN } 15 & \operatorname{EUR}(415) * \mathrm{~L} & 0 & 0.1\end{array}$ FLOW \#18 AIN $17 \quad \operatorname{EUR}(417) * \mathrm{~B} \quad 0 \quad 100$ FLOW \# 19 


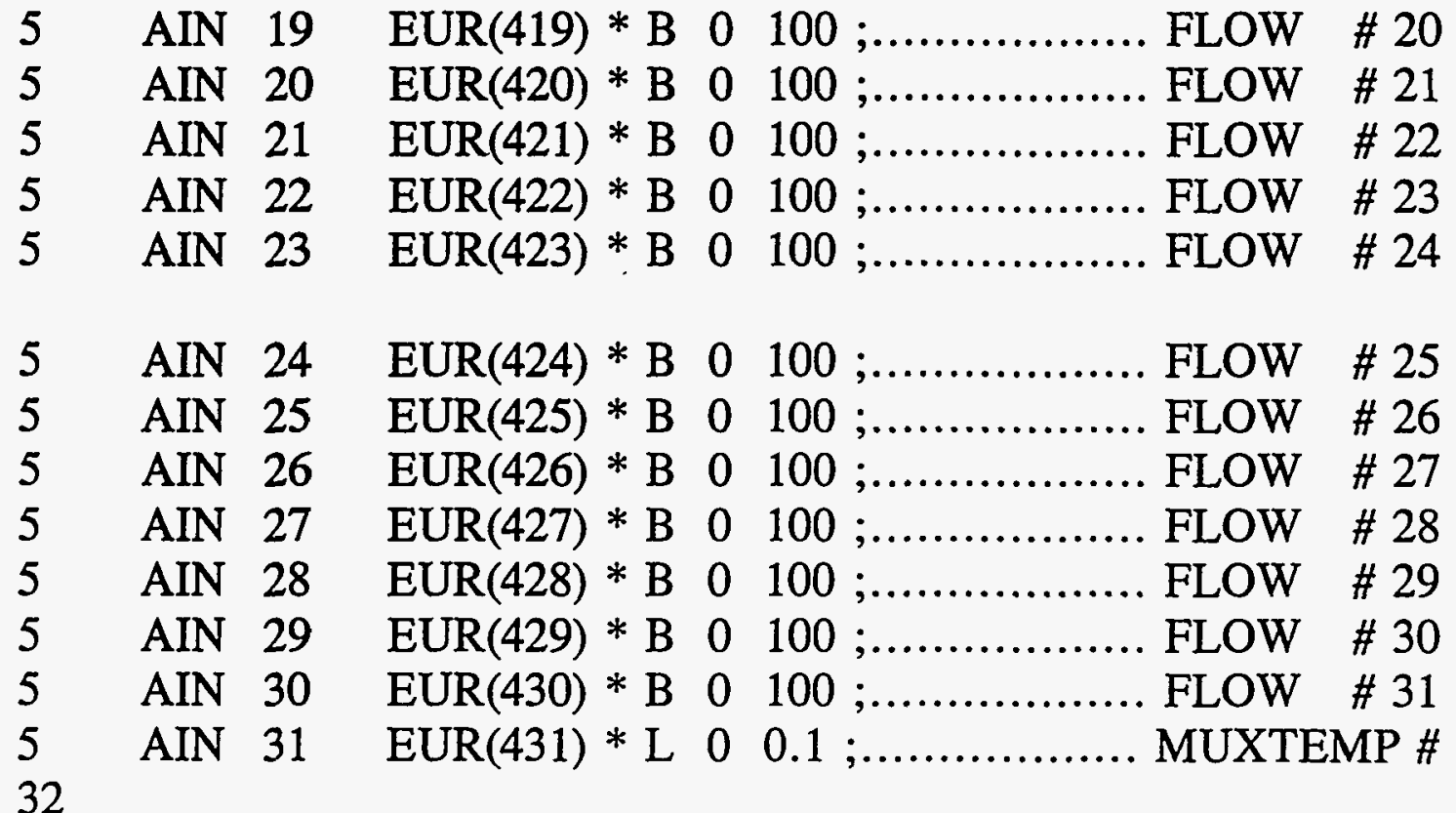

; EURS FOR WASTE MONITOR JUNCTION BOX \#2 PF-4 BASEMENT (A-06)

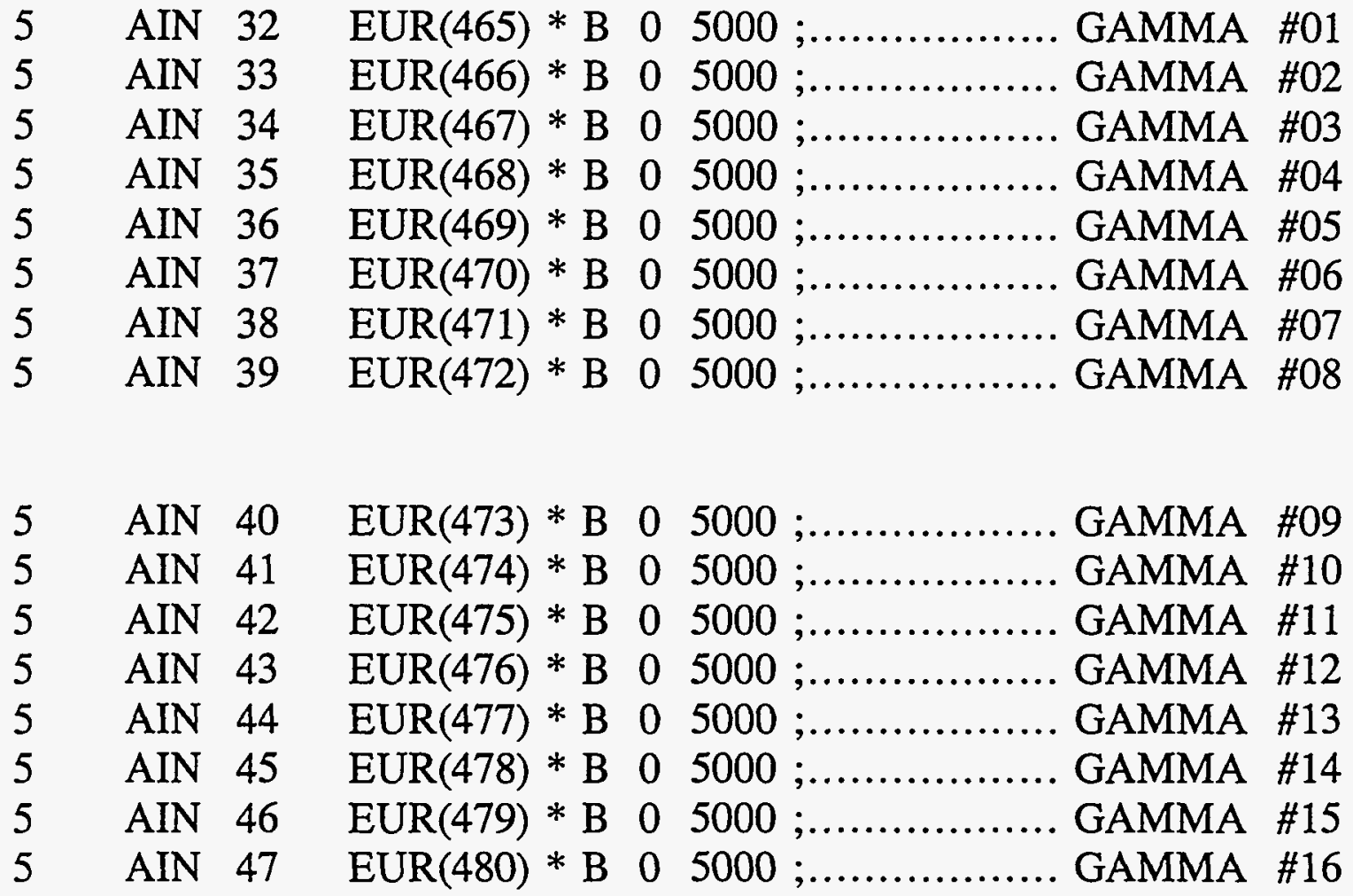




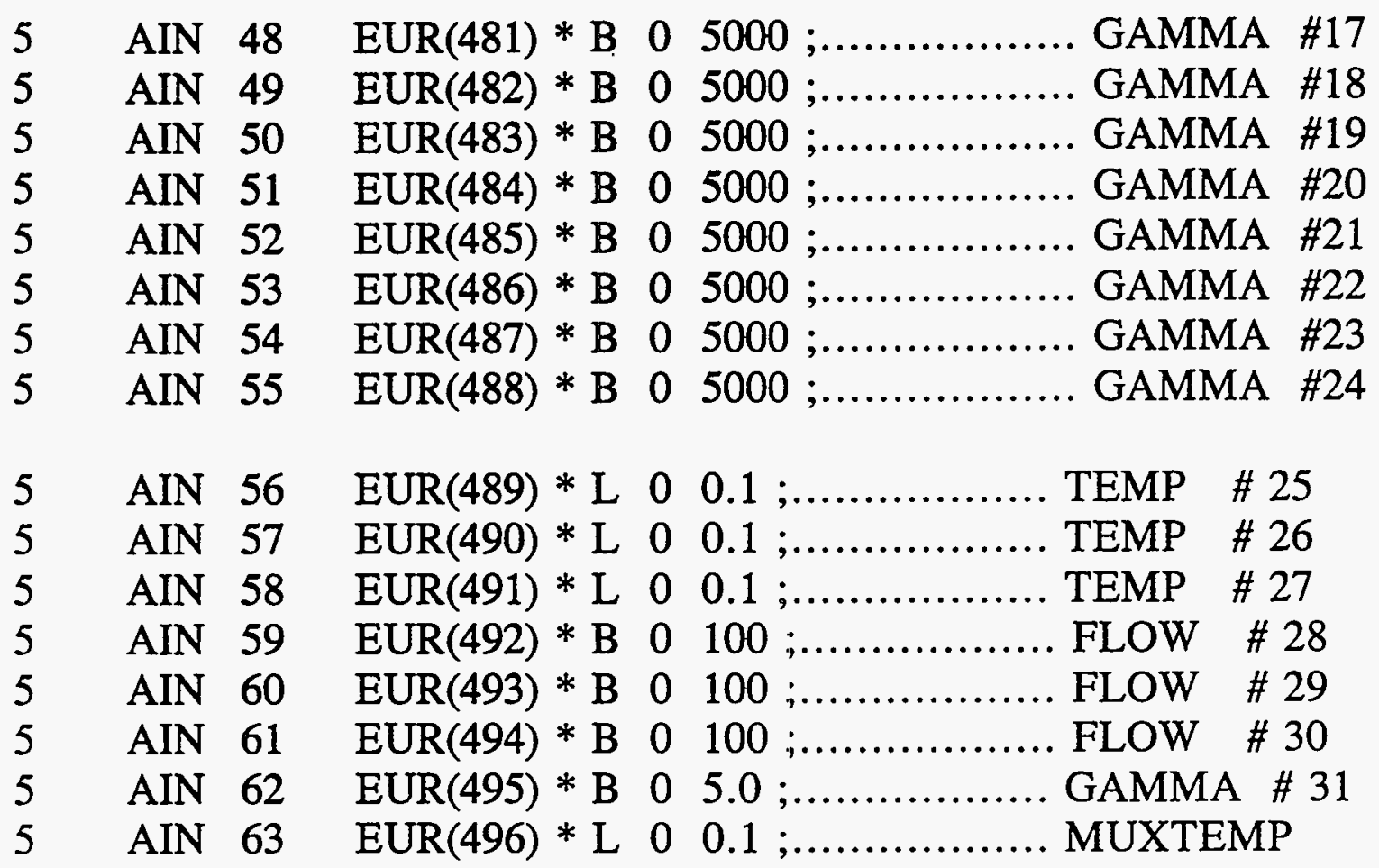

\section{; OUTPUT LIST}

$\begin{array}{lllll}\text { I } & \text { DOUT } & 0 & \text { DOO[400] } & * \\ \text { I } & \text { DOUT } & 1 & \text { DOO[401] } & * \\ \text { I } & \text { DOUT } & 2 & \text { DOO[402] } & * \\ \text { I } & \text { DOUT } & 3 & \text { DOO[403] } & * \\ \text { I } & \text { DOUT } & 4 & \text { DOO[404] } & * \\ \text { I } & \text { DOUT } & 5 & \text { DOO[405] } & * \\ \text { I } & \text { DOUT } & 6 & \text { DOO[406] } & * \\ \text { I } & \text { DOUT } & 7 & \text { DOO }[407] & *\end{array}$

END. 
Appendix D: LSO Configuration waste.cfg File

\section{Appendix D}

LSO Configuration waste.cfg File 


\section{LSO Configuration waste.cfg File}

The following is the LSO configuration text waste.cfg file.

;system configuration definition

COMPUTERNAME $=$ waste

FUNCTION $=$ CONSOLE

CYCLESUSPEND $=500$

WRITESUSPEND $=50$

NETWORK $=$ ON

;REMOTE INFO

STATION $=$ SOUNDER

PROTOCOL $=$ NETBIOS

CLASS $=$ MASTER

\section{NTLIST}

;Network TAG List for this node

;ALIAS

TABLE START END DRIVER TAGGED

SOURCE GLOBAL

WASTE_EUR

WASTE DOO

WASTE DII

WASTE_FLG

$\begin{array}{lllllll}\text { EUR } & 400 & 599 & Y & Y & Y & N \\ \text { DOO } & 400 & 599 & Y & N & Y & N \\ \text { DII } & 400 & 599 & Y & N & Y & N \\ \text { FLG } & 400 & 599 & Y & Y & Y & N\end{array}$

\$STA WASTE

\$IN_WASTE

FLG $37403740 \quad N$

EUR $3740 \quad 3740 \quad \mathrm{~N}$

$\begin{array}{lll}N & Y & N\end{array}$

\$OUTT WASTE

EUR $37413741 \quad N$

ONSPECC_WASTE

FLG

$127 \quad 127 \mathrm{~N}$

$N$

$Y$

$N$

$N$

LSO_WASTE

LOG_WASTE

SEC_WASTE

FLG $118 \quad 118 \quad \mathrm{~N}$

$\begin{array}{llll}\text { STR } & 110 & 110 & \mathrm{~N}\end{array}$

EUI

110

110

DRIVE1_WASTE

DII

128

$128 \mathrm{~N}$

$N$

$\begin{array}{ll}Y & N \\ Y & N\end{array}$

$\begin{array}{lll}N & Y & N \\ N & Y & N \\ N & Y & N \\ N & Y & N\end{array}$


INPUT

;CYCLE

1

; Network Tag List for this input condition

CONDITION

*

OUTPUT

;CYCLE

1

CONDITION

; Network Tag List for this output condition

WASTE EUR

WASTE DOO

WASTE_DII

WASTE_FLG

\$STA WASTE

\$IN WASTE

\$OŪT WASTE

ONSPEC_WASTE

LSO WASTE

LOG WASTE

SEC WASTE

DRIV̄E1_WASTTE 